\title{
A Short Review on the Effect of Surfactants on the Mechanico-Thermal Properties of Polymer Nanocomposites
}

\author{
Ahmad Adlie Shamsuri ${ }^{1, *(1)}$ and Siti Nurul Ain Md. Jamil ${ }^{2,3, *(1)}$ \\ 1 Laboratory of Biocomposite Technology, Institute of Tropical Forestry and Forest Products, Universiti Putra \\ Malaysia, UPM Serdang, Selangor 43400, Malaysia \\ 2 Department of Chemistry, Faculty of Science, Universiti Putra Malaysia, UPM Serdang, \\ Selangor 43400, Malaysia \\ 3 Centre of Foundation Studies for Agricultural Science, Universiti Putra Malaysia, UPM Serdang, \\ Selangor 43400, Malaysia \\ * Correspondence: adlie@upm.edu.my (A.A.S.); ctnurulain@upm.edu.my (S.N.A.M.J.)
}

Received: 29 May 2020; Accepted: 16 June 2020; Published: 16 July 2020

check for updates

\begin{abstract}
The recent growth of nanotechnology consciousness has enhanced the attention of researchers on the utilization of polymer nanocomposites. Nanocomposite have widely been made by using synthetic, natural, biosynthetic, and synthetic biodegradable polymers with nanofillers. Nanofillers are normally modified with surfactants for increasing the mechanico-thermal properties of the nanocomposites. In this short review, two types of polymer nanocomposites modified by surfactants are classified, specifically surfactant-modified inorganic nanofiller/polymer nanocomposites and surfactant-modified organic nanofiller/polymer nanocomposites. Moreover, three types of surfactants, specifically non-ionic, anionic, and cationic surfactants that are frequently used to modify the nanofillers of polymer nanocomposites are also described. The effect of surfactants on mechanico-thermal properties of the nanocomposites is shortly reviewed. This review will capture the interest of polymer composite researchers and encourage the further enhancement of new theories in this research field.
\end{abstract}

Keywords: surfactant; mechanico-thermal; polymer; nanocomposites

\section{Introduction}

Recently, the development of polymer nanocomposites in the composite industry has grown rapidly because they have superb mechanico-thermal properties and are very promising replacements for conventional polymer composites. Polymer nanocomposites are polymers incorporated with nanometer scale fillers, regardless of the origin of the materials, whether it is inorganic or organic. Synthetic polymers (examples are displayed in Table 1) are frequently utilized for the creation of polymer nanocomposites, including HDPE [1], PP [2], PS [3,4], DGEBA [5-7], PEVA [8,9], PBO [10], SR [11], PAN [12], PUA [13], etc. Synthetic biodegradable polymers (examples are also displayed in Table 1), such as PLA [14-18], PBAT [19], PBS [20], PVA [21], PCL [22], etc., are also utilized for nanocomposite preparation. 
Table 1. Examples of synthetic polymers and synthetic biodegradable polymers used in the preparation of polymer nanocomposites.

\begin{tabular}{cccc}
\hline Synthetic Polymer & Abbreviation & Synthetic Biodegradable Polymer & Abbreviation \\
\hline High-density polyethylene & HDPE & Poly(lactic acid) & PLA \\
Polypropylene & PP & Poly(butylene adipate-co-terephthalate) & PBAT \\
Polystyrene & PS & Poly(butylene succinate) & PBS \\
Diglycidyl ether of bisphenol A & DGEBA & Polyvinyl alcohol & PVA \\
Poly(ethylene-co-vinyl acetate) & PEVA & Poly(e-caprolactone) & PCL \\
Polybenzoxazine & PBO & & \\
Silicone rubber & SR & & \\
Polyacrylonitrile & PAN & & \\
Polyurethane acrylate & PUA & & \\
Thermoplastic polyurethane & TPU & & \\
Epoxy-terminated dimethylsiloxane & EDTS & & \\
\hline
\end{tabular}

On the other hand, nanofillers (examples are displayed in Table 2), such as MMT [2,9,12,20], Ag NPs [17,18], ZnO NPs [15], $\mathrm{TiO}_{2}$ NRs [3], CNTs [10,23,24], CNFs [5,25,26], G NPs [11,13,23], GO NSs [6,27], LDHs [22], and HNTs [4], are used in the fabrication of polymer nanocomposites, as they possess a high aspect ratio, large surface area, high stiffness, and low density $[17,20]$. The application of bio-based nanofillers, for example, CNCs [15,18,28,29], CNPs [30], NCFs [8,19], and CNWs $[7,16]$, also contribute to the production of nanocomposites because they are renewable and sustainable materials.

Table 2. Examples of nanofillers and surfactants used in the preparation of polymer nanocomposites.

\begin{tabular}{|c|c|c|c|}
\hline Nanofiller & Abbreviation & Surfactant & Abbreviation \\
\hline Montmorillonite & MMT & Hexadecyltrimethylammonium bromide & HTAB \\
\hline Silver nanoparticles & Ag NPs & Didodecyldimethylammonium bromide & DDAB \\
\hline Zinc oxide nanoparticles & $\mathrm{ZnO} \mathrm{NPs}$ & Sodium dodecyl sulfate & SDS \\
\hline Titanium dioxide nanorods & $\mathrm{TiO}_{2} \mathrm{NRs}$ & Polypropylene glycol ethoxylated and propoxylated & Ultraric PE 105 \\
\hline Carbon nanotubes & CNTs & Silicon-based surfactant & Niax L-595 \\
\hline Carbon nanofibers & CNFs & Bis-(2-hydroxyethyl)methyltallowalkylammonium chloride & HMAC \\
\hline Graphene nanoplatelets & G NPs & Polyoxyethylene octyl phenyl ether & Triton X-100 \\
\hline Graphene oxide nanosheets & GO NSs & Acid phosphate ester of ethoxylated nonylphenol & Beycostat A B09 \\
\hline Layered double hydroxides & LDHs & Lauric arginate & LAE \\
\hline Halloysite nanotubes & HNTs & Poly(ethylene glycol) monooleate & PEGMONO \\
\hline $\begin{array}{l}\text { Expanded graphite } \\
\text { nanoplatelets }\end{array}$ & EG NPs & $\begin{array}{l}\text { Triblock copolymers of poly(ethylene oxide) and } \\
\text { poly(propylene oxide) }\end{array}$ & Pluronic \\
\hline Cellulose nanocrystals & CNCs & Oleic acid & $\mathrm{OA}$ \\
\hline Cellulose nanoparticles & CNPs & Polysiloxane-polyether copolymer & AK8805 \\
\hline Nanocellulose fibers & NCFs & Stearic acid & SA \\
\hline \multirow[t]{6}{*}{ Cellulose nanowhiskers } & CNWs & Palmitic acid & PA \\
\hline & & Sorbitan monostearate & Span 60 \\
\hline & & Benzimidazolium-N,N'-hexadecane-2-hydroxy-ethyl bromide & ВНHВ \\
\hline & & Poly(ethylene glycol) & PEG \\
\hline & & Dodecylbenzene sulfonic acid & DBSA \\
\hline & & Sodium cholate & SC \\
\hline
\end{tabular}

Surfactants (examples are also displayed in Table 2), for instance, HTAB [13,20,31], DDAB [12,32], SDS [4,21], Ultraric PE 105 [19], Niax L-595 [8], HMAC [9], Triton X-100 [6,10,11,24], Beycostat A B09 [15,17,18,28], LAE [29], PEGMONO [14,16], Pluronic [7,14], OA [3], AK8805 [5], SA [2], PA [22], Span 60 [30], and BHHB [1], are commonly employed for modifying nanofillers in the preparation of polymer nanocomposites.

Surfactants have an amphiphilic character, owing to hydrophilic and hydrophobic functional groups $[33,34]$. Previous studies have indicated that the surfactants could act as interaction links between hydrophilic and hydrophobic polymers [35-37]. Furthermore, the presence of surfactants in polymer nanocomposites not only increased the uniformity of the nanofillers dispersion [8], but also improved the compatibility and wettability between polymer and nanofiller [11], as well as enhanced the final properties of the nanocomposites [18]. 
In the past few decades, many modification methods have been suggested for the purpose of increasing the mechanico-thermal properties (e.g., tensile strength, flexural strength, impact strength, degradation temperature, glass transition temperature, melting temperature, etc.) of polymer nanocomposites. The non-covalent surface modification method, by utilizing surfactants, is an effective way to modify nanofillers for enhancing the mechanico-thermal properties of polymer nanocomposites. Nonetheless, to the authors' knowledge, no short review has been made covering the work on surfactant-modified inorganic and organic nanofillers for polymer nanocomposites. That is the aim of conducting a systematic review in this paper. This short review is broad, albeit not comprehensive, but is completed with other relevant literatures.

\section{Types of Surfactant-Modified Polymer Nanocomposites}

\subsection{Surfactant-Modified Inorganic Nanofiller/Polymer Nanocomposites}

Table 3 indicates the examples of inorganic nanofillers, surfactants, polymer matrices, and preparation processes of polymer nanocomposites. An inorganic filler, such as MMT, could be modified by a cationic surfactant, like HMAC, to produce organoclay (OMMT) [9]. OMMT was incorporated into PEVA via melt blending and compression molding processes for the preparation of OMMT/PEVA nanocomposites [9]. $\mathrm{TiO}_{2} \mathrm{NRs}$ have also been used for the preparation of polymer nanocomposites. $\mathrm{TiO}_{2}$ NRs could be modified or capped by an anionic surfactant, such as OA, to prevent aggregation in solution [3]. The OA-capped $\mathrm{TiO}_{2} \mathrm{NRs}$ were mixed with PS solution via the solvent blending technique, followed by a drop casting process to prepare the $\mathrm{TiO}_{2} / \mathrm{PS}$ nanocomposites [3]. Other than clay mineral and metal oxide nanomaterials, the CNTs, G NPs, and GO NSs are also categorized as inorganic nanofillers. Although carbon is an organic material, the allotropes of carbon, such as CNTs, G NPs, and GO NSs, are considered as inorganic nanomaterials [38]. CNTs could be modified by a non-ionic surfactant, like Triton X-100, to improve dispersion in a PBO matrix [10]. CNT/PBO nanocomposites were prepared through solvent-free blending and pour casting processes at an elevated temperature [10].

Table 3. Examples of inorganic nanofillers, surfactants, polymer matrices, and preparation processes of polymer nanocomposites.

\begin{tabular}{cccccc}
\hline Inorganic Nanofiller & Surfactant & Polymer Matrix & Mixing Process & Final Process & References \\
\hline MMT & HMAC & PEVA & Melt blending & Compression molding & {$[9]$} \\
$\mathrm{TiO}_{2} \mathrm{NRs}$ & OA & PS & Solvent blending & Drop casting & {$[3]$} \\
$\mathrm{CNTs}$ & Triton X-100 & PBO & Solvent-free blending & Pour casting & {$[10]$} \\
CNFs & AK8805 & DGEBA & Solution blending & Compression molding & {$[5]$} \\
G NPs & Triton X-100 & SR & Solution blending & Compression molding & {$[11]$} \\
GO NSs & Triton X-100 & DGEBA & Solution blending & Pour casting & {$[6]$} \\
\hline
\end{tabular}

CNFs are also regarded as an inorganic nanofiller due to their preparation procedure and structure, which are the same as in CNTs, but CNFs have a larger diameter than CNTs [25]. CNFs could be modified by a silicone surfactant, like AK8805, to improve the dispersion of CNFs in an epoxy matrix, such as DGEBA [5]. CNF/DGEBA nanocomposites were prepared through solution blending and compression molding processes at an elevated temperature [5]. On the other hand, G NPs could also be modified by Triton X-100 via sonication in the solvent [11]. Modified G NPs were mixed with an SR solution through the solution blending process, followed by a compression molding process for vulcanization to obtain G NP/SR nanocomposites [11]. In addition, Triton X-100 could treat GO NSs to promote dispersion in a DGEBA matrix [6]. GO NS/DGEBA nanocomposites could also be prepared by means of solution blending and pour casting processes [6]. Table 3 demonstrates that the surfactant-modified inorganic nanofiller/polymer nanocomposites could be prepared by using typical polymer composite processing procedures without requiring complicated or complex preparation processes. 


\subsection{Surfactant-Modified Organic Nanofiller/Polymer Nanocomposites}

Table 4 indicates the examples of organic nanofillers, surfactants, polymer matrices, and preparation processes of polymer nanocomposites. Organic fillers, such as $\mathrm{CNCs}$, could be modified by an anionic surfactant, like Beycostat A B09, to produce surfactant-modified CNCs (s-CNCs) [15]. The s-CNCs were mixed with PLA via solution blending and solvent casting processes for the preparation of s-CNC/PLA nanocomposites [15]. CNPs have also been used for the preparation of polymer nanocomposites. CNPs could be modified by a non-ionic surfactant, such as Span 60, to improve the dispersion of hydrophilic CNPs in a hydrophobic PS matrix [30]. Span 60-modified CNPs were mixed with a PS solution via the solution blending process, followed by a solvent casting process to prepare CNP/PS nanocomposites [30]. On the other hand, NCFs could be suspended in a silicon-based surfactant, such as Niax L-595, with dispersant oils to facilitate the dispersion of NCFs in a PEVA matrix [8]. The NCF suspension was added to the PEVA through the melt blending process, followed by a compression molding process to obtain NCF/PEVA nanocomposites [8].

Table 4. Examples of organic nanofillers, surfactants, polymer matrices, and preparation processes of polymer nanocomposites.

\begin{tabular}{cccccc}
\hline Organic Nanofiller & Surfactant & Polymer Matrix & Mixing Process & Final Process & References \\
\hline CNCs & Beycostat A B09 & PLA & Solution blending & Solvent casting \\
CNPs & Span 60 & PS & Solution blending & Solvent casting & {$[15]$} \\
NCFs & Niax L-595 & PEVA & Melt blending & Compression molding & {$[30]$} \\
CNWs & Pluronic & DGEBA & Solvent-free blending & Pour casting & {$[7]$} \\
NCFs & Ultraric PE 105 & PBAT & Solution blending & Solvent casting & {$[19]$} \\
CNWs & PEGMONO & PLA & Solution blending & Solvent casting & {$[16]$} \\
\hline
\end{tabular}

In addition, Pluronic could treat $\mathrm{CNW}$ s to improve the interactions between the CNWs and the DGEBA epoxy [7]. CNW/DGEBA nanocomposites could be prepared by means of solvent-free blending and pour casting processes [7]. NCFs could also be modified by a non-ionic surfactant, like Ultraric PE 105, for promoting the interfacial interaction between the NCF and PBAT phases [19]. NCFs were mixed with the surfactant and PBAT via solution blending and solvent casting processes for the preparation of NCF/PBAT nanocomposites [19]. CNWs could also be modified by a non-ionic surfactant, such as PEGMONO, to improve CNW dispersion in a non-polar PLA matrix [16]. PEGMONO-modified CNWs were mixed with PLA solution via the solution blending process, followed by a solvent casting process to prepare CNW/PLA nanocomposites [16]. Table 4 demonstrates that the surfactant-modified organic nanofiller/polymer nanocomposites could mostly be prepared through a solvent casting process by using organic solvents.

\section{Effect of Surfactants on Mechanico-Thermal Properties}

\subsection{Types of Surfactants}

Surfactants have frequently been categorized into four types, namely non-ionic, anionic, cationic, and amphoteric. The categories are based on the polarity of the surfactant head group, for example, non-ionic, anionic, cationic, and amphoteric or zwitterionic. There is no charge on a head group of non-ionic surfactants, while anionic and cationic surfactants have negative and positive charges on their head groups, respectively. On the other hand, there are both negative and positive charges for the amphoteric surfactants [33]. Table 5 displays the types of surfactants, types of nanofillers, and modification methods for the preparation of polymer nanocomposites. Non-ionic surfactants, such as Triton X-100 (chemical structure showed in Figure 1a), could modify inorganic nanofillers like CNTs via an ultrasonication method to serve as a bridge between CNTs and DGEBA [24]. The NCF organic nanofiller could be modified with the non-ionic surfactant Ultraric PE 105 by mechanical stirring to improve the dispersion of NCFs in the nanocomposite [19]. 
Table 5. Types of surfactants, types of nanofillers, and modification methods for the preparation of polymer nanocomposites.

\begin{tabular}{cccccc}
\hline Surfactant & Type of Surfactant & Nanofiller & Type of Nanofiller & Modification Method & References \\
\hline Triton X-100 & Non-ionic & CNTs & Inorganic & Ultrasonication & {$[24]$} \\
Ultraric PE 105 & Non-ionic & NCFs & Organic & Stirring & {$[19]$} \\
SDS & Anionic & G NPs & Inorganic & Ultrasonication & {$[21]$} \\
Beycostat A B09 & Anionic & CNCs & Organic & Stirring & {$[18]$} \\
DDAB & Cationic & MMT & Inorganic & Agitation & {$[12]$} \\
HTAB & Cationic & CNCs & Organic & Stirring & {$[31]$} \\
\hline
\end{tabular}

(a)

(b)<smiles>CC(C)OCCC(C)Oc1ccc(C(C)(C)CC(C)(C)C)cc1</smiles><smiles>CCCCCCCCCCCCCCC[N+](C)(CCCCCCCCC)CCCCCCCCCCCC</smiles>

Figure 1. Chemical structures of (a) Triton X-100, (b) SDS, and (c) DDAB.

An anionic surfactant, for example, SDS (chemical structure showed in Figure 1b), is commonly employed in the modification of inorganic nanofillers, such as G NPs, through an ultrasonication method to assist G NP dispersion in a PVA matrix [21]. The CNC organic nanofiller could be modified with the anionic surfactant Beycostat A B09 by mechanical stirring to obtain stable dispersions of CNCs in nanocomposites [18]. On the other hand, cationic surfactants, for instance, DDAB (chemical structure showed in Figure 1c), could be utilized for the modification of inorganic nanofillers, such as MMT, via an agitation process [12]. CNCs could be modified with the cationic surfactant HTAB, also by mechanical stirring, for the preparation of such nanocomposites [31]. Table 5 also exhibits that the non-ionic, anionic, and cationic surfactants could modify both inorganic and organic nanofillers without any limitations. However, the modification of nanofillers by amphoteric surfactants is not only complicated [39], but also limited to inorganic nanofillers, such as MMT [40,41].

\subsection{Effect of Non-Ionic Surfactants}

Table 6 shows the mechanico-thermal properties of polymer nanocomposites modified by non-ionic surfactants. Pluronic (chemical structure showed in Figure 2a) could modify organic nanofillers like CNWs and modified CNWs have been used for the preparation of CNW/DGEBA nanocomposites [7]. The modification of CNWs has improved the mechanico-thermal properties of the nanocomposites. The mechanical properties, such as tensile strength, tensile modulus, and elongation at break, of the nanocomposites have increased by up to $79 \%, 27 \%$, and $77 \%$, respectively, compared to the unmodified CNW/DGEBA nanocomposite. This is attributed to the improved dispersion and enhanced 
interfacial interaction between the Pluronic-modified CNWs and the DGEBA matrix [7]. However, the degradation temperature of the nanocomposites decreased because of the presence of small aggregates of Pluronic-modified CNWs in the nanocomposites, which degraded easily in comparison with the large agglomerates. Furthermore, the glass transition temperature of the nanocomposites also decreased due to possible Pluronic micelle formation inside the DGEBA matrix [7].

Table 6. Mechanico-thermal properties of polymer nanocomposites modified by non-ionic surfactants.

\begin{tabular}{|c|c|c|c|c|c|c|c|c|c|c|c|c|c|}
\hline \multirow{2}{*}{$\begin{array}{l}\text { Non-ionic } \\
\text { Surfactant }\end{array}$} & \multirow{2}{*}{ Nanofiller } & \multirow{2}{*}{$\begin{array}{l}\text { Polymer } \\
\text { Matrix }\end{array}$} & \multicolumn{10}{|c|}{ Mechanico-Thermal Properties * } & \multirow{2}{*}{ References } \\
\hline & & & TS & TM & EB & FS & FM & IS & $T_{\mathrm{d}}$ & $T_{\mathrm{g}}$ & $T_{\mathrm{m}}$ & $T_{\mathrm{c}}$ & \\
\hline Pluronic & CNWs & DGEBA & $\uparrow$ & $\uparrow$ & $\uparrow$ & - & - & - & $\downarrow$ & $\downarrow$ & - & - & [7] \\
\hline PEGMONO & CNCs & PLA & $\downarrow$ & - & $\downarrow$ & - & - & - & $\uparrow$ & - & - & - & {$[14,16]$} \\
\hline Triton X-100 & CNTs & $\mathrm{PBO}$ & - & - & - & $\uparrow$ & $\uparrow$ & $\uparrow$ & - & $\uparrow$ & $\uparrow$ & - & [10] \\
\hline AK8805 & CNFs & DGEBA & $\uparrow$ & $\uparrow$ & - & - & - & $\uparrow$ & $\uparrow$ & $\uparrow$ & - & - & [5] \\
\hline Triton X-100 & G NPs & SR & $\uparrow$ & $\uparrow$ & $\uparrow$ & - & - & - & $\uparrow$ & - & $\downarrow$ & $\downarrow$ & [11] \\
\hline Ultraric PE 105 & NCFs & PBAT & $\uparrow$ & $\uparrow$ & - & - & - & - & $\downarrow$ & - & - & - & [19] \\
\hline
\end{tabular}

TS = tensile strength, $\mathbf{T M}=$ tensile modulus, $\mathbf{E B}=$ elongation at break, $\mathbf{F S}=$ flexural strength, $\mathbf{F M}=$ flexural modulus, IS = impact strength, $T_{\mathrm{d}}=$ degradation temperature, $\boldsymbol{T}_{\mathrm{g}}=$ glass transition temperature, $\boldsymbol{T}_{\mathrm{m}}=$ melting temperature, and $T_{\mathbf{c}}=$ crystallization temperature. ${ }^{*}$ The symbol $\uparrow$ corresponds to an increase in the properties and $\downarrow$ a decrease in the properties while "-" means "not available".

(a)<smiles>[Y]C(C)(CCOC(C)(C)O)OC(C)CC(C)(C)OCCC(C)(C)O</smiles>

(b)<smiles>CCCCCCCC/C=C/CCCCCCCC(=O)OC(C)(C)CCOC(C)C</smiles>

Figure 2. Chemical structures of (a) Pluronic and (b) PEGMONO.

PEGMONO (chemical structure showed in Figure 2b) could modify organic nanofillers such as CNCs and modified CNCs have been utilized for the preparation of CNC/PLA nanocomposites [14]. The modification improved the maximum degradation temperature of the nanocomposites up to $0.6 \%$ compared to neat PLA [16]. This is attributed to the higher thermal stability of PEGMONO, which covered the surface of the CNCs and prevented the modified CNCs from decomposing quickly [14]. Nevertheless, the tensile strength of the nanocomposites decreased in comparison with the nanocomposite without PEGMONO; this is because of the presence of CNC/PEGMONO aggregates. Moreover, the elongation at break of the nanocomposites slightly decreased, as PEGMONO improved CNC interaction with the PLA matrix [14].

On the other hand, Triton X-100 could modify inorganic nanofillers like CNTs and modified CNTs have been applied for the preparation of CNT/PBO nanocomposites [10]. The modification of CNTs improved the mechanico-thermal properties of the nanocomposites, such as flexural strength, flexural modulus, impact strength, glass transition temperature, and melting temperature. The flexural strength, flexural modulus, and impact strength increased by up to $31 \%, 10 \%$, and $13 \%$, respectively, compared to the unmodified CNT/PBO nanocomposite, which was due to strong hydrophobic attraction between the hydrophobic segment of Triton X-100 and the surface of the CNTs, whereas the hydrophilic segment of Triton X-100 interacted with the PBO matrix through hydrogen 
bonding [10]; both interactions improved the wettability and reduced surface tension of the CNTs in the nanocomposites. Moreover, the glass transition temperature and melting temperature increased by up to $1.0 \%$ and $0.6 \%$, respectively, which was also because of the improved interfacial interaction between the Triton X-100-modified CNTs and the PBO matrix, as well as the improved degree of dispersion of the modified CNTs in the nanocomposites [10].

AK8805 could modify inorganic nanofillers like CNFs and the modified CNFs have been used for the preparation of CNF/DGEBA nanocomposites [5]. The modification of CNFs improved the mechanico-thermal properties of the nanocomposites. The mechanical properties, such as tensile strength, tensile modulus, and impact strength, of the nanocomposites increased by up to $20 \%, 165 \%$, and $15 \%$, respectively, compared to the neat DGEBA, which was due to enhancement of the interaction between the modified CNFs and the DGEBA matrix [5]. Furthermore, the degradation temperature and glass transition temperature of the nanocomposites also increased by up to $4.5 \%$ and $2.7 \%$, respectively, because of the better dispersion of CNFs caused by the enhanced interaction [5].

Triton X-100 could also modify inorganic nanofillers such as G NPs and modified G NPs have been utilized for the preparation of G NP/SR nanocomposites [11]. The modification of G NPs improved the tensile strength, tensile modulus, and elongation at break by up to $20 \%, 5.4 \%$, and $22 \%$, respectively. This is attributed to the capability of the surfactant to act as a bridge between the G NPs and the SR matrix, which subsequently improved the compatibility and wettability of the graphene platelets and this provided a good adhesion to the SR [11]. The maximum degradation temperature of the nanocomposites also improved by up to $3.0 \%$ due to the good Triton X-100-G NP/SR interface interaction that offered a better barrier effect [11]. Nonetheless, the melting temperature and crystallization temperature of the nanocomposites insignificantly decreased compared to the nanocomposite without Triton X-100 because of Triton X-100 does not link with the crystal structure.

On the other hand, Ultraric PE 105 could modify organic nanofillers like NCFs and modified NCFs have been applied for the preparation of NCF/PBAT nanocomposites [19]. The modification of NCFs slightly improved the mechanical properties of the nanocomposites, such as tensile strength and Young's modulus, by up to $8.9 \%$ and $4.4 \%$, respectively, compared to the unmodified NCF/PBAT nanocomposite. The minor increase was probably related to the excess of Ultraric PE 105 in the nanocomposites, which influenced the exerted force on the nanocomposites [19]. Moreover, the degradation temperature of the nanocomposites decreased because Ultraric PE 105 has a lower molecular weight than PBAT, which consequently affected its thermal stability [19]. Table 6 clearly displays that the modification of inorganic and organic nanofillers by non-ionic surfactants improved the mechanico-thermal properties of the prepared polymer nanocomposites, regardless of the type of the non-ionic surfactant.

\subsection{Effect of Anionic Surfactants}

Table 7 shows the mechanico-thermal properties of polymer nanocomposites modified by anionic surfactants. SA (chemical structure showed in Figure 3a) could modify inorganic nanofillers like MMT and modified MMTs have been used for the preparation of MMT/PP nanocomposites [2]. The modification of MMT improved the mechanico-thermal properties of the nanocomposites. The mechanical properties, such as tensile strength, elongation at break, and impact strength, of the nanocomposites increased by up to $5.3 \%, 125 \%$, and $50 \%$, respectively. This is due to the dispersion state of SA-MMT being very good [2]. In contrast, the Young's modulus of the nanocomposites decreased because the tougher the composites, the less stiff their character. The melting temperature of the nanocomposites slightly increased by up to $1.0 \%$ due to the strengthening of mechanical properties of the nanocomposites. However, the crystallization temperature of the nanocomposites decreased compared to the nanocomposite without SA because of the very good dispersion of SA-MMT in the nanocomposites [2]. 
Table 7. Mechanico-thermal properties of polymer nanocomposites modified by anionic surfactants.

\begin{tabular}{|c|c|c|c|c|c|c|c|c|c|c|c|c|c|}
\hline \multirow{2}{*}{$\begin{array}{c}\text { Anionic } \\
\text { Surfactant }\end{array}$} & \multirow{2}{*}{ Nanofiller } & \multirow{2}{*}{$\begin{array}{c}\text { Polymer } \\
\text { Matrix }\end{array}$} & \multicolumn{10}{|c|}{ Mechanico-Thermal Properties * } & \multirow{2}{*}{ References } \\
\hline & & & TS & TM & EB & IS & SM & LM & $T_{\mathrm{d}}$ & $T_{\mathrm{g}}$ & $T_{\mathrm{m}}$ & $T_{\mathrm{c}}$ & \\
\hline SA & MMT & PP & $\uparrow$ & $\downarrow$ & $\uparrow$ & $\uparrow$ & - & - & - & - & $\uparrow$ & $\downarrow$ & [2] \\
\hline OA & $\mathrm{TiO}_{2} \mathrm{NRs}$ & PS & - & - & - & - & $\downarrow$ & $\uparrow$ & $\uparrow$ & $\downarrow$ & - & - & [3] \\
\hline PA & LDHs & PCL & $\downarrow$ & $\uparrow$ & - & \begin{tabular}{|l|}
$\uparrow$ \\
\end{tabular} & $\uparrow$ & $\uparrow$ & - & $\downarrow$ & $\uparrow$ & $\uparrow$ & [22] \\
\hline SDS & HNTs & PS & - & - & - & $\uparrow$ & $\uparrow$ & - & $\uparrow$ & $\downarrow$ & - & - & [4] \\
\hline Beycostat A B09 & CNCs & PLA & $\uparrow$ & $\uparrow$ & $\downarrow$ & - & - & - & $\uparrow$ & $\downarrow$ & $\downarrow$ & $\downarrow$ & [18] \\
\hline SDS & G NPs & PVA & $\uparrow$ & $\uparrow$ & $\uparrow$ & - & - & - & $\uparrow$ & - & $\downarrow$ & $\uparrow$ & [21] \\
\hline
\end{tabular}

TS = tensile strength, $\mathbf{T M}=$ tensile modulus, $\mathbf{E B}=$ elongation at break, IS = impact strength, $\mathbf{S M}=$ storage modulus, LM = loss modulus, $T_{\mathrm{d}}=$ degradation temperature, $T_{\mathrm{g}}=$ glass transition temperature, $\boldsymbol{T}_{\mathrm{m}}=$ melting temperature, and $T_{\mathrm{c}}=$ crystallization temperature. ${ }^{*}$ The symbol $\uparrow$ corresponds to an increase in the properties and $\downarrow$ a decrease in the properties while "-" and $\uparrow$ mean "not available" and "unchanged", respectively.

(a)

(b)

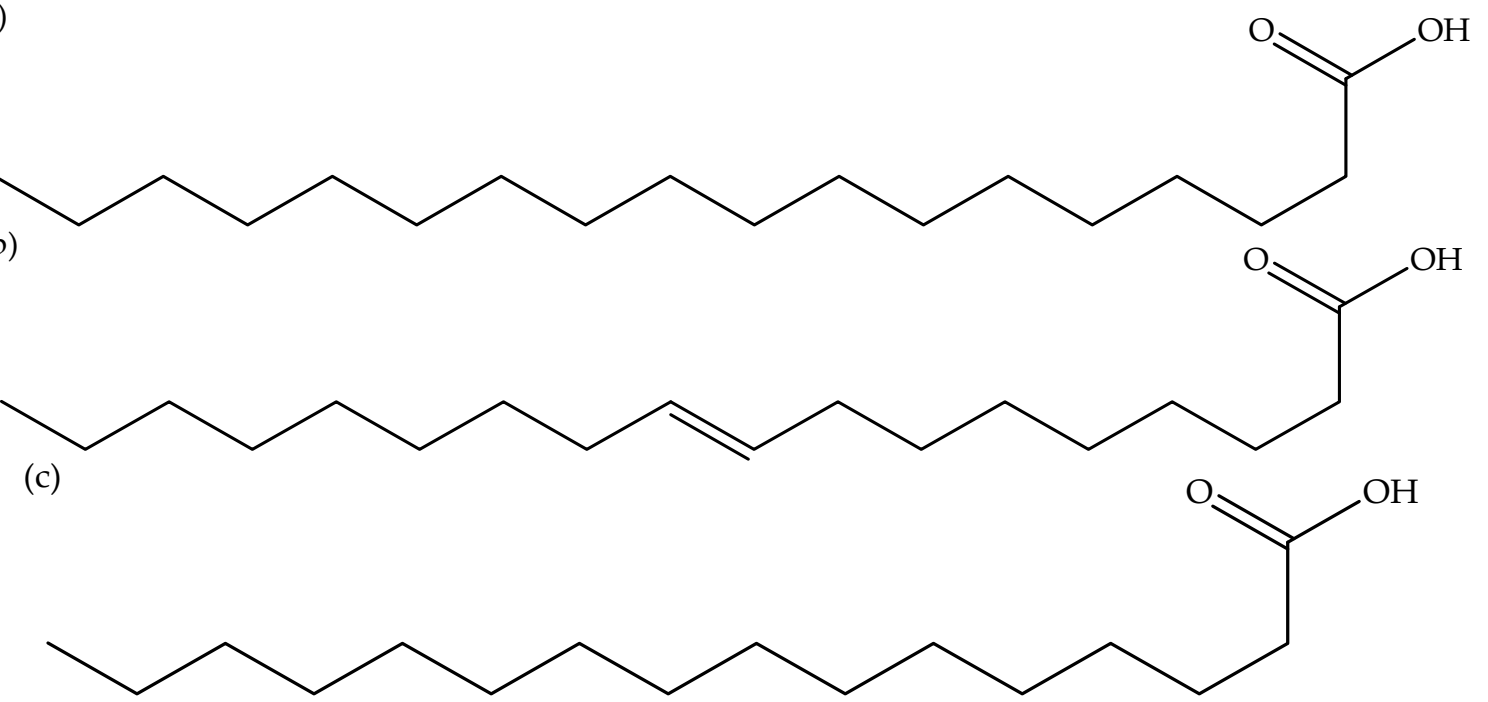

Figure 3. Chemical structures of (a) SA, (b) OA, and (c) PA.

$\mathrm{OA}$ (chemical structure showed in Figure 3b) could modify inorganic nanofillers, such as $\mathrm{TiO}_{2}$ NRs, to prevent the agglomeration of $\mathrm{TiO}_{2} \mathrm{NRs}$ and modified $\mathrm{TiO}_{2} \mathrm{NRs}$ have been utilized for the preparation of $\mathrm{TiO}_{2} \mathrm{NR} / \mathrm{PS}$ nanocomposites [3]. The modification of $\mathrm{TiO}_{2} \mathrm{NRs}_{\text {improved the loss }}$ modulus of the nanocomposites by up to $22 \%$ compared to neat PS. This is attributed to the PS chains becoming softer due to the presence of $\mathrm{OA}$-modified $\mathrm{TiO}_{2}$. [3]. Moreover, the glass transition temperature of the nanocomposite decreased because of the soft PS chains caused by the OA molecules. In addition, the storage modulus of the nanocomposite decreased due to the plasticization effect of OA, which is present at the $\mathrm{TiO}_{2} \mathrm{NR}$ surface [3]. Nevertheless, the maximum degradation temperature of the nanocomposites increased by up to $1.3 \%$ because the thermal stability of the $\mathrm{TiO}_{2} \mathrm{NRs}$ was more than $400^{\circ} \mathrm{C}$.

On the other hand, PA (chemical structure showed in Figure 3c) could modify inorganic nanofillers like LDHs and modified LDHs have been applied for the preparation of LDH/PCL nanocomposites [22]. The modification of LDHs improved the mechanico-thermal properties of the nanocomposites, such as tensile modulus, impact strength, storage modulus, and crystallization temperature. The tensile modulus and impact strength properties increased by up to $12 \%$ and $65 \%$, respectively, compared to the neat PCL, which was due to the reinforcement property of the PA-modified LDHs (PA-LDHs), and they could also act as an impact strength modifier in the nanocomposite system. Moreover, the storage 
modulus of the nanocomposites increased by up to $9.1 \%$, which was because of a favorable dispersion and interaction between the PA-LDH nanofiller and the PCL matrix [22]. The loss modulus of the nanocomposites also increased by up to $10 \%$ due to the plasticizing effect of the PA-LDHs. Additionally, the crystallization temperature of the nanocomposites increased by up to $3.0 \%$, which could possibly be attributed to the PA-LDHs, which acted as heterogeneous nucleation sites in the PCL matrix. However, the tensile strength of the nanocomposites decreased because of the presence of tactoids at a high content of PA-LDHs, which may act as stress concentrations [22]. In addition, the glass transition temperature of the nanocomposites also decreased due to improved PCL chain mobility, and it is probable that it would enhance in free volume.

SDS could modify inorganic nanofillers such as HNTs and modified HNTs have been used for the preparation of HNT/PS nanocomposites [4]. The modification of HNTs improved the mechanico-thermal properties of the nanocomposites. The mechanical properties, for example, impact strength and storage modulus, increased by up to $203 \%$ and $39 \%$, respectively, with the addition of HNTs compared to neat PS. This is because the HNTs could improve of the stiffness of the nanocomposites [4]. Furthermore, the degradation temperature of the nanocomposites also increased by up to $14 \%$ due to the entrapment of decomposition products by the HNT lumen. Nonetheless, the glass transition temperature of the nanocomposites decreased because of the presence of interactions between the HNTs and PS [4].

Beycostat A B09 could modify organic nanofillers like CNCs and modified CNCs have been utilized for the preparation of CNC/PLA nanocomposites [18]. The modification of CNCs improved the mechanical properties of the nanocomposites, such as tensile strength and tensile modulus. The tensile strength and tensile modulus increased by up to $63 \%$ and $50 \%$, respectively, which was attributed to the Beycostat A B09 efficiently dispersing CNCs in the PLA matrix [18]. However, the decrease in the elongation at break of the nanocomposites was due to the CNCs initiating considerable local stress concentrations and then failure at lowered strain values. Moreover, the decrease in crystallization temperature was because of the presence of Beycostat A B09 on the CNC surface, which caused a better dispersion of the CNCs in the PLA matrix, which certainly increased the nucleation effect on the nanocomposites [18]. Nonetheless, the other thermal properties, for instance, the glass transition temperature and melting temperature, decreased insignificantly compared to the nanocomposite without Beycostat A B09.

On the other hand, SDS could also modify inorganic nanofillers like G NPs and modified G NPs have been applied for the preparation of G NP/PVA nanocomposites [21]. The modification of G NPs improved the mechanical properties of the nanocomposites, such as tensile strength and tensile modulus, by up to $75 \%$ and $154 \%$, respectively, compared to neat PVA. The substantial increases were due to the SDS aiding the dispersion of G NPs, which maximized the load transfer from PVA to the G NPs. Moreover, the elongation at break of the nanocomposites also increased by up to $53 \%$ because of the slippage of the intercalated state of G NP dispersion in the PVA matrix during tensile testing [21]. Additionally, the degradation temperature and crystallization temperature of the nanocomposites also increased by up to $0.8 \%$ and $1.6 \%$, respectively, even at a low content of SDS-modified G NPs. This due to a heterogenous nucleating effect, which was caused by the adsorption of SDS into the G NPs [21]. Nevertheless, the melting temperature of the nanocomposites decreased, which was related to the decrease in their degree of crystallinity. Table 7 clearly displays that the modification of inorganic and organic nanofillers by anionic surfactants improved the mechanico-thermal properties of the prepared polymer nanocomposites, regardless of the type of anionic surfactant.

\subsection{Effect of Cationic Surfactant}

Table 8 shows the mechanico-thermal properties of polymer nanocomposites modified by cationic surfactants. HTAB (chemical structure showed in Figure 4a) could modify inorganic nanofillers like MMT and modified MMTs have been used for the preparation of MMT/PBS nanocomposites [20]. The modification of MMT improved the mechanico-thermal properties of the nanocomposites. The mechanical properties, such as tensile strength, tensile modulus, elongation at break, flexural 
strength, flexural modulus, and impact strength, of the nanocomposites increased by up to $34 \%$, $7.3 \%, 210 \%, 34 \%, 3.6 \%$, and $66 \%$, respectively, compared to the unmodified MMT/PBS nanocomposite. This is due to the presence of trimethyl groups in HTAB that eased the MMT dispersion and offered a better reinforcement effect. Additionally, the high aspect ratio of HTAB-modified MMTs provided a higher surface area to interact with the PBS matrix [20]. Furthermore, the melting temperature also improved by up to $2.3 \%$ because of the higher degree of crystallinity of the nanocomposites. In addition, the crystallization temperature also increased by up to $6.5 \%$ due to the improved modified MMTs and the PBS matrix interactions and better filler dispersion [20].

Table 8. Mechanico-thermal properties of polymer nanocomposites modified by cationic surfactants.

\begin{tabular}{|c|c|c|c|c|c|c|c|c|c|c|c|c|c|c|}
\hline \multirow{2}{*}{$\begin{array}{l}\text { Cationic } \\
\text { Surfactant }\end{array}$} & \multirow{2}{*}{ Nanofiller } & \multirow{2}{*}{$\begin{array}{c}\text { Polymer } \\
\text { Matrix }\end{array}$} & \multicolumn{11}{|c|}{ Mechanico-Thermal Properties * } & \multirow{2}{*}{ References } \\
\hline & & & TS & TM & EB & FS & FM & IS & SM & $T_{\mathrm{d}}$ & $T_{\mathrm{g}}$ & $T_{\mathrm{m}}$ & $T_{\mathrm{c}}$ & \\
\hline HTAB & MMT & PBS & $\uparrow$ & $\uparrow$ & $\uparrow$ & $\uparrow$ & $\uparrow$ & $\uparrow$ & - & - & - & $\uparrow$ & $\uparrow$ & [20] \\
\hline LAE & $\mathrm{CNCs}$ & PLA & $\uparrow$ & $\uparrow$ & $\uparrow$ & - & - & - & $\uparrow$ & - & $\uparrow$ & $\uparrow$ & $\downarrow$ & [29] \\
\hline HMAC & MMT & PEVA & - & - & - & - & - & - & $\overline{\imath \uparrow}$ & - & - & $\downarrow$ & $\downarrow$ & [9] \\
\hline HТAB & G NPs & PUA & - & - & - & - & - & - & $\uparrow$ & $\uparrow$ & $\uparrow$ & - & - & [13] \\
\hline BHHB & MMT & HDPE & $\uparrow$ & $\uparrow$ & $\downarrow$ & - & - & - & $\uparrow$ & $\uparrow$ & - & - & - & [1] \\
\hline DDAB & MMT & PS & $\uparrow$ & $\uparrow$ & $\uparrow$ & - & - & - & - & $\uparrow$ & - & - & - & [32] \\
\hline
\end{tabular}

TS = tensile strength, $\mathbf{T M}=$ tensile modulus, $\mathbf{E B}=$ elongation at break, $\mathbf{F S}=$ flexural strength, $\mathbf{F M}=$ flexural modulus, IS = impact strength, $\mathrm{SM}=$ storage modulus, $\boldsymbol{T}_{\mathrm{d}}=$ degradation temperature, $\boldsymbol{T}_{\mathrm{g}}=$ glass transition temperature, $T_{\mathrm{m}}=$ melting temperature, and $T_{\mathrm{c}}=$ crystallization temperature. * The symbol $\uparrow$ corresponds to an increase in the properties and $\downarrow$ a decrease in the properties while "-" means "not available".

(a)

(b)<smiles>NCCCCCCCCCCCCCCCI</smiles>

(c)<smiles>[3H][N+](C)(CCO)CCO</smiles>

Figure 4. Chemical structures of (a) HTAB, (b) LAE, and (c) HMAC. 
LAE (chemical structure showed in Figure 4 b) could modify organic nanofillers such as CNCs and modified CNCs have been utilized for the preparation of CNC/PLA nanocomposites [29]. The modification of CNCs increased the tensile strength, Young's modulus, and strain at break by up to $91 \%, 78 \%$, and $58 \%$, respectively. This could probably be attributed to the result of improved crystallinity and the enhanced dispersion/interface compatibility of LAE-modified CNCs within the PLA matrix. Additionally, the storage modulus of the nanocomposites increased by up to $69 \%$; this could be associated with the creation of a stiff continuous modified CNC percolation network and the modified CNCs, which prompted the limitation of the PLA chain movement [29]. Furthermore, the glass transition temperature and melting temperature also improved by up to $15 \%$, and $1.4 \%$, respectively, due to the increased modified CNC dispersion and interface compatibility, which efficiently restricted the movement of PLA chains. In contrast, the crystallization temperature of the nanocomposites decreased compared to the nanocomposite without LAE because of the strong nucleating effect of modified CNCs, which promoted crystallization [29].

On the other hand, HMAC (chemical structure showed in Figure 4c) could modify inorganic nanofillers like MMT and modified MMTs have been applied for the preparation of MMT/PEVA nanocomposites [9]. The modification of MMT improved the mechanical properties of the nanocomposites, such as storage modulus. The storage modulus of the nanocomposites increased by up to $340 \%$, due to strong HMAC-modified MMT and PEVA interactions compared to the nanocomposite without HMAC [9]. However, the melting temperature of the nanocomposites decreased due to the presence of HMAC, which offered interactions between the modified MMTs and the PEVA matrix [9]. Moreover, the crystallization temperature of the nanocomposites also decreased because the crystallization kinetics were altered by modified MMTs, which diminished the crystal perfection of the PEVA matrix.

HTAB could also modify inorganic nanofillers like G NPs and modified G NPs have been used for the preparation of G NPs/PUA nanocomposites [13]. The modification of G NPs improved the mechanico-thermal properties of the nanocomposites. The storage modulus of the nanocomposites increased by up to $104 \%$ compared to the neat PUA; this could be attributed to a high aspect ratio of HTAB-modified G NPs with high surface areas dispersed evenly in the PUA matrix and forming strong interfacial interactions with the matrix via hydrogen bonding [13]. Furthermore, the degradation temperature of the nanocomposites improved by up to $23 \%$ due to the high thermal stability of modified G NPs that acted as an efficient physical barrier, which hindered thermal decomposition by slowing down the vaporization of volatile molecules. Moreover, the glass transition temperature of the nanocomposites also increased by up to $554 \%$ because of the physical barrier effect of the crumpled modified G NPs, which induced mechanical interlocking with PUA chains, and subsequently confined segmental movements at the modified G NP-PUA interface [13].

BHHB could modify inorganic nanofillers such as MMT and modified MMTs have been utilized for the preparation of MMT/HDPE nanocomposites [1]. The modification of MMT improved the tensile strength and Young's modulus by up to $31 \%$ and $66 \%$, respectively, compared to the neat HDPE; this is attributed to the homogeneous distribution and a large aspect ratio of BHHB-modified MMTs that induced the strong interfacial interaction between modified MMTs and the HDPE matrix for better interfacial stress transfer efficiency. Nonetheless, the elongation at break of the nanocomposites significantly decreased because of the cross-section of HDPE resisted deformation, which was efficiently reduced by the modified MMTs [1]. The storage modulus of the nanocomposites increased by up to $99 \%$ because an interconnected network of modified MMTs within the HDPE matrix formed, which restricted the long-range movement of HDPE chains. Moreover, the degradation temperature of the nanocomposite improved by up to $5.3 \%$ because the modified MMTs acted as a mass transport barrier to the volatile products generated during thermal decomposition [1].

On the other hand, DDAB could also modify inorganic nanofillers like MMT and modified MMTs have been applied for the preparation of MMT/PS nanocomposites [32]. The modification of MMT improved the mechanical properties of the nanocomposites, such as tensile strength, Young's modulus, 
and elongation at break, by up to $32 \%, 30 \%$, and $18 \%$, respectively, compared to the unmodified MMT/PS nanocomposite. The increases were related to the exceptional dispersion of DDAB-modified MMTs in the PS matrix and the remarkable adhesion between the modified MMTs and the PS [32]. Moreover, the degradation temperature of the nanocomposites also increased by up to $7.1 \%$, possibly because DDAB, with two long alkyl chains, could provide outstanding thermal stability [32]. Table 8 clearly displays that the modification of inorganic and organic nanofillers by cationic surfactants has improved the mechanico-thermal properties of the prepared polymer nanocomposites, regardless of the type of the cationic surfactant.

\subsection{Effect of Surfactants on Thermal Conductivity}

Table 9 displays the effect of different types of surfactants on the thermal conductivity of polymer nanocomposites. The thermal conductivity of G NP/SR nanocomposites increased by up to $14 \%$ when the G NPs were modified with Triton X-100. The increase is due to the modified G NPs that have a good dispersion and good interface in the nanocomposites [11]. The thermal conductivity of CNT/PS nanocomposites increased by up to $202 \%$ when the CNTs were modified with a non-ionic surfactant, such as PEG (chemical structure showed in Figure 5a). The increase is because the modified CNTs have a more even dispersion character, which was acquired through ultrasonic dispersion with PEG [42]. The thermal conductivity of CNT/SR nanocomposites increased by up to $38 \%$ when the CNTs were modified with an anionic surfactant like DBSA (chemical structure showed in Figure 5b). The increase is because the modified CNTs have a good homogeneity, which creates a large interface area with SR [43].

On the other hand, the thermal conductivity of CNT/TPU nanocomposites increased by up to $2971 \%$ when the CNTs were modified with an anionic surfactant, such as SC (chemical structure showed in Figure 5c). The increase is because the modified CNTs were smaller and had a fine distribution that generated effective interactions with the TPU matrix [44]. The thermal conductivity of EG NP/PEVA nanocomposites increased by up to $137 \%$ when the EG NPs were modified with SDS. The increase is because the modified EG NPs have a better dispersion, which formed the constant EG NP pathways [45]. The thermal conductivity of GO NS/EDTS nanocomposites increased by up to $404 \%$ when the GO NSs were modified with HTAB. The increase is because the modified GO NSs formed a thin, finely dispersed layer, which created an uninterrupted heat flux pathway and interacted with the EDTS matrix [46]. Table 9 clearly shows that the modification of inorganic nanofillers by non-ionic, anionic, and cationic surfactants has increased the thermal conductivity of the prepared polymer nanocomposites.

Table 9. Effect of different types of surfactants on the thermal conductivity of polymer nanocomposites.

\begin{tabular}{ccccc}
\hline Surfactant & Nanofiller & Polymer Matrix & Thermal Conductivity & References \\
\hline Triton X-100 & G NPs & SR & $\uparrow(14 \%)$ & {$[11]$} \\
PEG & CNTs & PS & $\uparrow(202 \%)$ & {$[42]$} \\
DBSA & CNTs & SR & $\uparrow(38 \%)$ & {$[43]$} \\
SC & CNTs & TPU & $\uparrow(2971 \%)$ & {$[44]$} \\
SDS & EG NPs & PEVA & $\uparrow(137 \%)$ & {$[45]$} \\
HTAB & GO NSs & EDTS & $\uparrow(404 \%)$ & {$[46]$} \\
\hline
\end{tabular}


(a)

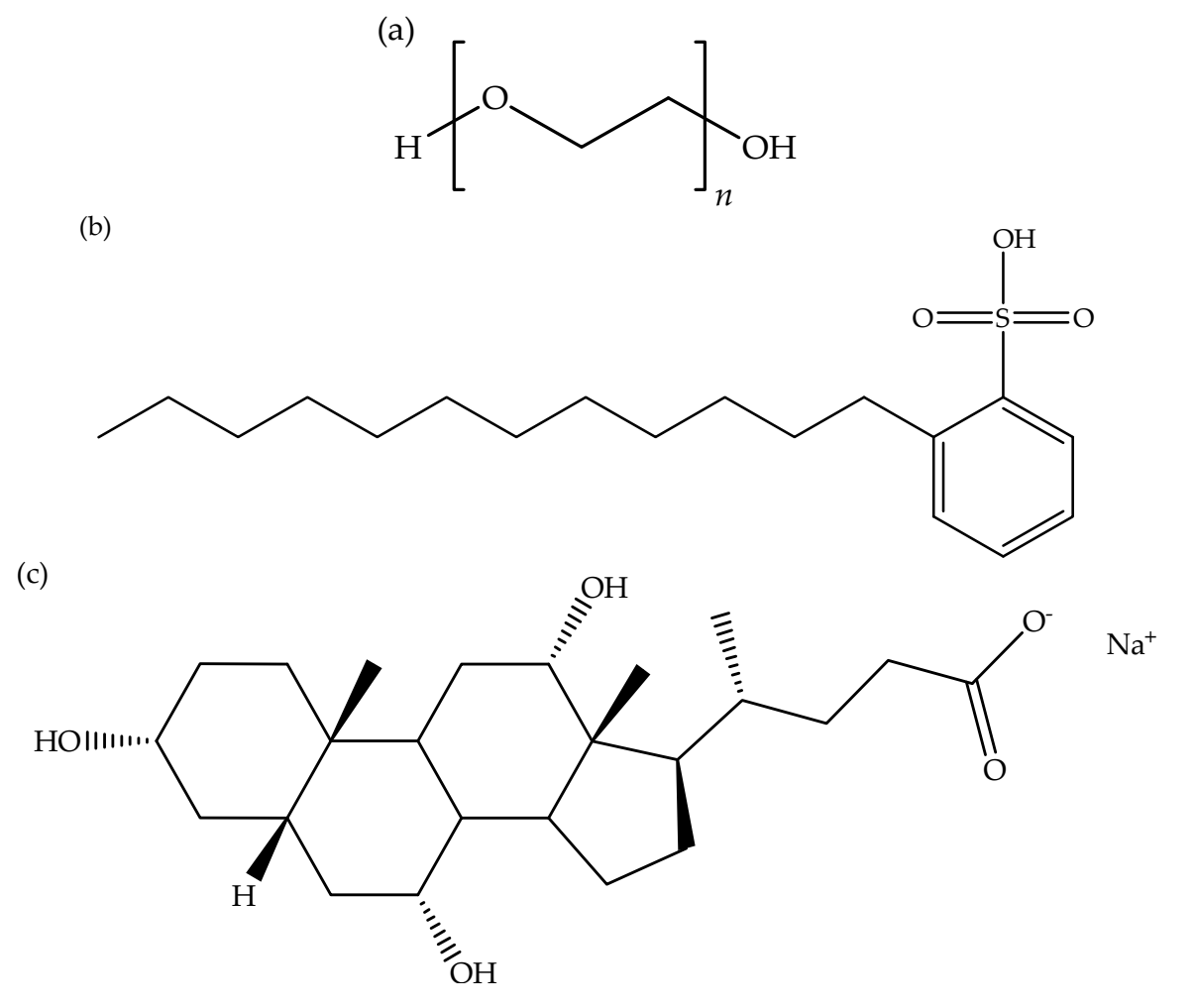

Figure 5. Chemical structures of (a) PEG, (b) DBSA, and (c) SC.

\section{Conclusions}

Nanofillers, polymer matrices, preparation procedures, and the mechanico-thermal properties of polymer nanocomposites modified with surfactants have been briefly reviewed in this paper. The primary mechanico-thermal properties, for instance, tensile strength, flexural strength, impact strength, degradation temperature, glass transition temperature, and the melting temperature of the nanocomposites, have also been described in this short review. Surfactants have regularly been applied for the modification of nanofillers because they possess an amphiphilic character. Surfactants utilized for different types of polymer nanocomposites are mostly based on their chemical structures. In addition, non-ionic, anionic, and cationic surfactants have been the three most significant surfactants for the improvement of the mechanico-thermal properties of polymer nanocomposites. Non-ionic surfactants are typically used in the modification of organic nanofillers, such as nanocelluloses. Anionic and cationic surfactants are frequently employed in the modification of inorganic nanofillers, like metal oxides, MMT, etc. The proper modification of nanofillers by surfactants could improve the dispersion of the nanofillers in the polymer matrices. Moreover, the surfactant-modified inorganic and organic nanofillers could effectively form strong interactions between the nanofillers and the polymer matrices. This short review might be beneficial, not only for polymer composite researchers, but also be useful for the commercialization of polymer nanocomposites for various applications.

Author Contributions: Conceptualization, A.A.S. and S.N.A.M.J.; methodology, A.A.S.; validation, A.A.S. and S.N.A.M.J.; formal analysis, S.N.A.M.J.; investigation, A.A.S.; resources, S.N.A.M.J.; data curation, A.A.S.; writing-original draft preparation, A.A.S.; writing-review and editing, S.N.A.M.J.; project administration, A.A.S.; funding acquisition, S.N.A.M.J. All authors have read and agreed to the published version of the manuscript.

Funding: This short review was funded by the Universiti Putra Malaysia under the Grant Putra IPM Scheme (project number: GP-IPM/2017/9579900).

Acknowledgments: The authors would like to thank the Laboratory of Biocomposite Technology, Institute of Tropical Forestry and Forest Products, Universiti Putra Malaysia. 
Conflicts of Interest: The authors declare no conflict of interest. The funder had no role in the design of the review; in the collection, analyses, or interpretation of data; in the writing of the manuscript, or in the decision to publish the results.

\section{References}

1. El Achaby, M.; Ennajih, H.; Arrakhiz, F.Z.; El Kadib, A.; Bouhfid, R.; Essassi, E.; Qaiss, A. Modification of montmorillonite by novel geminal benzimidazolium surfactant and its use for the preparation of polymer organoclay nanocomposites. Compos. Part B 2013, 51, 310-317. [CrossRef]

2. Gonzalez, L.; Lafleur, P.; Lozano, T.; Morales, A.B.; Garcia, R.; Angeles, M.; Rodriguez, F.; Sanchez, S. Mechanical and thermal properties of polypropylene/montmorillonite nanocomposites using stearic acid as both an interface and a clay surface modifier. Polym. Compos. 2014, 35, 1-9. [CrossRef]

3. Patra, N.; Salerno, M.; Cozzoli, P.D.; Athanassiou, A. Surfactant-induced thermomechanical and morphological changes in TiO2-polystyrene nanocomposites. J. Colloid Interface Sci. 2013, 405, $103-108$. [CrossRef] [PubMed]

4. $\quad$ Lin, Y.; Ng, K.M.; Chan, C.M.; Sun, G.; Wu, J. High-impact polystyrene/halloysite nanocomposites prepared by emulsion polymerization using sodium dodecyl sulfate as surfactant. J. Colloid Interface Sci. 2011, 358, 423-429. [CrossRef]

5. Li, J.; Zhang, G.; Shang, Z.; Fan, X.; Zhang, H.; Zhou, L.; Shi, X. Enhanced electromagnetic interference shielding and mechanical properties of foamed epoxy nanocomposites containing carbon nanofiber treated with silicone surfactant. J. Appl. Polym. Sci. 2018, 135, 46833-46843. [CrossRef]

6. Zang, J.; Wan, Y.J.; Zhao, L.; Tang, L.C. Fracture behaviors of TRGO-filled epoxy nanocomposites with different dispersion/interface levels. Macromol. Mater. Eng. 2015, 300, 737-749. [CrossRef]

7. Emami, Z.; Meng, Q.; Pircheraghi, G.; Manas-Zloczower, I. Use of surfactants in cellulose nanowhisker/epoxy nanocomposites: Effect on filler dispersion and system properties. Cellulose 2015, 22, 3161-3176. [CrossRef]

8. Zimmermann, M.V.G.; da Silva, M.P.; Zattera, A.J.; Campomanes Santana, R.M. Effect of nanocellulose fibers and acetylated nanocellulose fibers on properties of poly (ethylene-co-vinyl acetate) foams. J. Appl. Polym. Sci. 2017, 134, 44760-44771. [CrossRef]

9. Marini, J.; Branciforti, M.C.; Lotti, C. Effect of matrix viscosity on the extent of exfoliation in EVA/organoclay nanocomposites. Polym. Adv. Technol. 2010, 21, 408-417. [CrossRef]

10. Kaleemullah, M.; Khan, S.U.; Kim, J.K. Effect of surfactant treatment on thermal stability and mechanical properties of CNT/polybenzoxazine nanocomposites. Compos. Sci. Technol. 2012, 72, 1968-1976. [CrossRef]

11. Zhang, G.; Wang, F.; Dai, J.; Huang, Z. Effect of functionalization of graphene nanoplatelets on the mechanical and thermal properties of silicone rubber composites. Materials 2016, 9, 92. [CrossRef] [PubMed]

12. Hwang, J.J.; Ma, T.W. Preparation, morphology, and antibacterial properties of polyacrylonitrile/ montmorillonite/silver nanocomposites. Mater. Chem. Phys. 2012, 136, 613-623. [CrossRef]

13. Xu, J.; Cai, X.; Shen, F. Preparation and property of UV-curable polyurethane acrylate film filled with cationic surfactant treated graphene. Appl. Surf. Sci. 2016, 379, 433-439. [CrossRef]

14. Góis, G.S.; Nepomuceno, N.C.; França, C.H.; Almeida, Y.M.; Hernandéz, E.P.; Oliveira, J.E.; Oliveira, M.P.; Medeiros, E.S.; Santos, A.S. Influence of morphology and dispersion stability of CNC modified with ethylene oxide derivatives on mechanical properties of PLA-based nanocomposites. Polym. Compos. 2019, 40, E399-E408. [CrossRef]

15. Luzi, F.; Fortunati, E.; Jiménez, A.; Puglia, D.; Chiralt, A.; Torre, L. PLA nanocomposites reinforced with cellulose nanocrystals from Posidonia oceanica and $\mathrm{ZnO}$ nanoparticles for packaging application. J. Renew. Mater. 2017, 5, 103-115. [CrossRef]

16. Gois, G.D.S.; Andrade, M.F.D.; Garcia, S.M.S.; Vinhas, G.M.; Santos, A.S.; Medeiros, E.S.; Oliveira, J.E.; Almeida, Y.M.B.D. Soil biodegradation of PLA/CNW nanocomposites modified with ethylene oxide derivatives. Mater. Res. 2017, 20, 899-904. [CrossRef]

17. Fortunati, E.; Armentano, I.; Zhou, Q.; Puglia, D.; Terenzi, A.; Berglund, L.A.; Kenny, J.M. Microstructure and nonisothermal cold crystallization of PLA composites based on silver nanoparticles and nanocrystalline cellulose. Polym. Degrad. Stab. 2012, 97, 2027-2036. [CrossRef] 
18. Fortunati, E.; Armentano, I.; Zhou, Q.; Iannoni, A.; Saino, E.; Visai, L.; Berglund, L.A.; Kenny, J.M. Multifunctional bionanocomposite films of poly (lactic acid), cellulose nanocrystals and silver nanoparticles. Carbohydr. Polym. 2012, 87, 1596-1605. [CrossRef]

19. Bauli, C.R.; Rocha, D.B.; dos Santos Rosa, D. Composite films of ecofriendly lignocellulosic nanostructures in biodegradable polymeric matrix. SN Appl. Sci. 2019, 1, 774-785. [CrossRef]

20. Phua, Y.J.; Chow, W.S.; Mohd Ishak, Z.A. Organomodification of montmorillonite and its effects on the properties of poly (butylene succinate) nanocomposites. Polym. Eng. Sci. 2013, 53, 1947-1957. [CrossRef]

21. Thayumanavan, N.; Tambe, P.B.; Joshi, G. Effect of surfactant and sodium alginate modification of graphene on the mechanical and thermal properties of polyvinyl alcohol (PVA) nanocomposites. Cellul. Chem. Technol. 2015, 49, 69-80.

22. Moyo, L.; Makhado, E.; Sinha Ray, S. Anomalous impact strength for layered double hydroxide-palmitate/poly (E-caprolactone) nanocomposites. J. Appl. Polym. Sci. 2014, 131, 41109-41118. [CrossRef]

23. Tkalya, E.E.; Ghislandi, M.; de With, G.; Koning, C.E. The use of surfactants for dispersing carbon nanotubes and graphene to make conductive nanocomposites. Curr. Opin. Colloid Interface Sci. 2012, 17, $225-232$. [CrossRef]

24. Geng, Y.; Liu, M.Y.; Li, J.; Shi, X.M.; Kim, J.K. Effects of surfactant treatment on mechanical and electrical properties of CNT/epoxy nanocomposites. Compos. Part A 2008, 39, 1876-1883. [CrossRef]

25. Rana, S.; Alagirusamy, R.; Joshi, M. Mechanical behavior of carbon nanofibre-reinforced epoxy composites. J. Appl. Polym. Sci. 2010, 118, 2276-2283. [CrossRef]

26. Rana, S.; Alagirusamy, R.; Joshi, M. Development of carbon nanofibre incorporated three phase carbon/epoxy composites with enhanced mechanical, electrical and thermal properties. Compos. Part A 2011, 42, 439-445. [CrossRef]

27. Wan, Y.J.; Tang, L.C.; Yan, D.; Zhao, L.; Li, Y.B.; Wu, L.B.; Jiang, J.X.; Lai, G.Q. Improved dispersion and interface in the graphene/epoxy composites via a facile surfactant-assisted process. Compos. Sci. Technol. 2013, 82, 60-68. [CrossRef]

28. Fortunati, E.; Peltzer, M.; Armentano, I.; Torre, L.; Jiménez, A.; Kenny, J.M. Effects of modified cellulose nanocrystals on the barrier and migration properties of PLA nano-biocomposites. Carbohydr. Polym. 2012, 90, 948-956. [CrossRef]

29. Chi, K.; Catchmark, J.M. Enhanced dispersion and interface compatibilization of crystalline nanocellulose in polylactide by surfactant adsorption. Cellulose 2017, 24, 4845-4860. [CrossRef]

30. Kim, J.; Montero, G.; Habibi, Y.; Hinestroza, J.P.; Genzer, J.; Argyropoulos, D.S.; Rojas, O.J. Dispersion of cellulose crystallites by nonionic surfactants in a hydrophobic polymer matrix. Polym. Eng. Sci. 2009, 49, 2054-2061. [CrossRef]

31. Kaboorani, A.; Auclair, N.; Riedl, B.; Landry, V. Physical and morphological properties of UV-cured cellulose nanocrystal (CNC) based nanocomposite coatings for wood furniture. Prog. Org. Coat. 2016, 93, 17-22. [CrossRef]

32. Lu, F.L.; Shen, M.X.; Xue, Y.J.; Zeng, S.H.; Chen, S.N.; Hao, L.Y.; Yang, L. Application of calcium montmorillonite on flame resistance, thermal stability and interfacial adhesion in polystyrene nanocomposites. e-Polymers 2019, 19, 92-102. [CrossRef]

33. Dzulkefly, K.; Khoh, H.F.; Ahmad, F.B.H.; Adlie Ahmad, S.; Lim, W.H. Solvent-free esterification process for the synthesis of glucose bolaform surfactants. Orient. J. Chem. 2010, 26, 747-752.

34. Shamsuri, A.A.; Daik, R.; Zainudin, E.S.; Tahir, P.M. Compatibilization of HDPE/agar biocomposites with eutectic-based ionic liquid containing surfactant. J. Reinf. Plast. Compos. 2014, 33, 440-453. [CrossRef]

35. Shamsuri, A.A.; Azid, M.K.A.; Ariff, A.H.M.; Sudari, A.K. Influence of surface treatment on tensile properties of low-density polyethylene/cellulose woven biocomposites: A preliminary study. Polymers 2014, 6, 2345-2356. [CrossRef]

36. Sudari, A.K.; Shamsuri, A.A.; Zainudin, E.S.; Tahir, P.M. Exploration on compatibilizing effect of nonionic, anionic, and cationic surfactants on mechanical, morphological, and chemical properties of high-density polyethylene/low-density polyethylene/cellulose biocomposites. J. Thermoplast. Compos. Mater. 2017, 30, 855-884. [CrossRef]

37. Shamsuri, A.A.; Md. Jamil, S.N.A. Compatibilization effect of ionic liquid-based surfactants on physicochemical properties of PBS/rice starch blends: An initial study. Materials 2020, 13, 1885. [CrossRef] 
38. Urie, R.; Ghosh, D.; Ridha, I.; Rege, K. Inorganic nanomaterials for soft tissue repair and regeneration. Annu. Rev. Biomed. Eng. 2018, 20, 353-374. [CrossRef]

39. McLauchlin, A.R.; Thomas, N.L. Preparation and thermal characterisation of poly (lactic acid) nanocomposites prepared from organoclays based on an amphoteric surfactant. Polym. Degrad. Stab. 2009, 94, 868-872. [CrossRef]

40. Wang, X.; Wang, Y.; Zhao, Z.; Zhu, X.; Nie, C.; Du, S. Preparation and characterization of exfoliated poly (ethyleneterephthalate)/montmorillonite nanocomposites using modified MMTs with variable content of antimony acetate. Chin. J. Chem. 2011, 29, 1278-1284. [CrossRef]

41. McLauchlin, A.R.; Thomas, N.L. Preparation and characterization of organoclays based on an amphoteric surfactant. J. Colloid Interface Sci. 2008, 321, 39-43. [CrossRef] [PubMed]

42. Yang, Y.; Gupta, M.C.; Zalameda, J.N.; Winfree, W.P. Dispersion behaviour, thermal and electrical conductivities of carbon nanotube-polystyrene nanocomposites. IET Micro Nano Lett. 2008, 3, 35-40. [CrossRef]

43. Vilčáková, J.; Moučka, R.; Svoboda, P.; Ilčíková, M.; Kazantseva, N.; Hřibová, M.; Mičušík, M.; Omastová, M. Effect of surfactants and manufacturing methods on the electrical and thermal conductivity of carbon nanotube/silicone composites. Molecules 2012, 17, 13157-13174. [CrossRef]

44. Yuan, S.; Bai, J.; Chua, C.K.; Wei, J.; Zhou, K. Highly enhanced thermal conductivity of thermoplastic nanocomposites with a low mass fraction of MWCNTs by a facilitated latex approach. Compos. Part A 2016, 90, 699-710. [CrossRef]

45. Sefadi, J.S.; Luyt, A.S.; Pionteck, J.; Piana, F.; Gohs, U. Effect of surfactant and electron treatment on the electrical and thermal conductivity as well as thermal and mechanical properties of ethylene vinyl acetate/expanded graphite composites. J. Appl. Polym. Sci. 2015, 132, 42396-42405. [CrossRef]

46. Oh, H.; Kim, K.; Ryu, S.; Kim, J. Enhancement of thermal conductivity of polymethyl methacrylate-coated graphene/epoxy composites using admicellar polymerization with different ionic surfactants. Compos. Part A 2019, 116, 206-215. [CrossRef]

(C) 2020 by the authors. Licensee MDPI, Basel, Switzerland. This article is an open access article distributed under the terms and conditions of the Creative Commons Attribution (CC BY) license (http://creativecommons.org/licenses/by/4.0/). 